\title{
KARAKTERISTIK PANCING TEGAK UNTUK MENANGKAP IKAN PELAGIS BESAR YANG DIOPERASIKAN DI PERAIRAN SELATAN BALI*)
}

\author{
Sawon ${ }^{1)}$ \\ 1) Teknisi Litkayasa pada Balai Riset Perikanan Laut, Muara Baru-Jakarta \\ Teregristasi I tanggal: 23 Juli 2008; Diterima setelah perbaikan tanggal: 24 Juli 2008; \\ Disetujui terbit tanggal: 25 Juli 2008
}

\section{PENDAHULUAN}

Benoa yang merupakan bagian dari Propinsi Bali secara geografis, terletak pada posisi $08^{\circ} 51^{\prime}$ LS dan $115^{\circ} 12^{\prime}$ BT. Perairan Benoa Bali, merupakan salah satu wilayah penyebaran jenis-jenis ikan pelagis dan demersal, seperti ikan layang (Decapterus spp.), lemuru (Sardinella sp.), cakalang (Katsuwonus pelamis), madidihang (Thunnus albacares), kakap merah (Lutjanus spp.), dan kurisi (Nemipterus spp.). Ikan-ikan tersebut merupakan hasil tangkapan utama di wilayah lepas pantai (off shore), khususnya di perairan Pejantan (dekat Pulau Nusa Penida). (Mertha, 2004).

Salah satu alat tangkap yang dioperasikan di perairan Benoa Bali adalah pancing tegak. Di samping itu, juga ada alat tangkap lain seperti pancing tonda, tuna long line, purse seine, gill net, dan jaring cumi. Pancing tegak adalah ramah lingkungan yang dioperasikan secara manual, ikan yang tertangkap antara 2,5 sampai dengan $6,5 \mathrm{~kg}$ per ekor, pada kedalaman air antara 40 sampai dengan $150 \mathrm{~m}$ (Uktolseja, 1972).
Tujuan penulisan ini adalah menyajikan data dan informasi mengenai dimensi teknis kapal, karakteristik, dan aspek operasional alat tangkap. Penelitian dilakukan terhadap pancing tegak yang sedang beroperasi di atas kapal motor milik nelayan setempat.

\section{POKOK BAHASAN}

\section{DESKRIPSI KAPAL DAN ALAT TANGKAP}

\section{Kapal}

Kapal yang dioperasikan dengan alat tangkap pancing tegak adalah kapal kayu dibuat oleh galangan kapal di Banyuwangi Jawa Timur antara tahun 2004 sampai dengan 2007. Dengan ukuran panjang (LOA) $12,0 \mathrm{~m}$; lebar (W) 2,10 m; dalam (D) 1,0 m; dan bobot kotor 6 GT; mesin Yanmar 15 PK, dengan kecepatan 5,5 knot. Pancing ditarik secara manual, lama melaut 7 hari, dan kapal ini diawaki oleh 5 orang anak buah kapal, yang terdiri atas 1 orang nahkoda kapal dan 4 orang pemancing (Tabel 1).

Tabel 1. Spesifikasi kapal di Benoa Bali, bulan Desember 2007

\begin{tabular}{|c|c|c|c|c|c|c|c|}
\hline \multirow{2}{*}{ No. } & \multirow{2}{*}{ Nama kapal } & \multicolumn{3}{|c|}{ Ukuran (m) } & \multirow{2}{*}{ GT } & \multirow{2}{*}{$\begin{array}{c}\text { Mesin } \\
\text { (PK) }\end{array}$} & \multirow{2}{*}{$\begin{array}{c}\text { Alat } \\
\text { tangkap }\end{array}$} \\
\hline & & LOA & $\mathbf{w}$ & D & & & \\
\hline 1. & KM. Tunas Harapan-02 & 12,00 & 2,10 & 1,00 & 6 & 15 & Pancing tegak \\
\hline 2. & KM. Putra Gonjeng-02 & 12,00 & 2,10 & 1,00 & 6 & 15 & Pancing tegak \\
\hline 3. & KM. Putra Gonjeng-01 & 12,00 & 2,10 & 1,00 & 6 & 15 & Pancing tegak \\
\hline 4. & KM. Sarinah & 12,00 & 2,10 & 1,00 & 6 & 15 & Pancing tegak \\
\hline 5. & KM. Tunas Harapan-07 & 12,00 & 2,10 & 1,00 & 6 & 15 & Pancing tegak \\
\hline
\end{tabular}

Sumber: Hasil wawancara dengan nahkoda kapal

\section{Desain Alat Tangkap}

Dimensi tiap unit pancing tegak di Benoa Bali secara umum terbagi dalam 9 bagian utama yaitu penggulung bulat dari sintetis diameter $15 \mathrm{~cm} \times$ panjang $30 \mathrm{~cm}$, tali utama monofilament diameter 2 $\mathrm{mm}$, panjang $200 \mathrm{~m}$, tali cabang monofilament diameter $0,5 \mathrm{~mm}$, panjang $50 \mathrm{~cm}$, mata pancing stainlis ukuran no.6, swivel stainlis panjang $4 \mathrm{~cm}$, pemberat timah $(\mathrm{Pb})$ bobot $0,5 \mathrm{~kg}$, pelampung bulat dari sintetis diameter $10 \mathrm{~cm}$, jarak antar pancing 4 $\mathrm{m}$, dan jarak dari pancing terakhir ke pemberat $2 \mathrm{~m}$.

Setiap kapal terdiri atas 10 penggulung yang masing-masing terdiri atas 7 buah mata pancing yang berarti jumlah 1 unit $=70$ mata pancing, tertera dalam Gambar 1.

\section{Bagian Utama}

1. Penggulung dari sintetis diameter $15 \mathrm{~cm} \times$ panjang $30 \mathrm{~cm}$.

2. Tali utama dari PA diameter $2 \mathrm{~mm} \times$ panjang $200 \mathrm{~m}$.

3. Tali cabang dari PA diameter $0,5 \mathrm{~mm} \times$ panjang $50 \mathrm{~cm}$.

4. Mata pancing dari stainlis no.6.

5. Swivel stainlis panjang $4 \mathrm{~cm}$.

6. Pemberat dari timah $(\mathrm{Pb}) \mathrm{a}^{\prime} 0,5 \mathrm{~kg}$.

7. Pelampung bulat dari sintetis diameter $10 \mathrm{~cm}$. 
8. Jarak antar pancing $4 \mathrm{~m}$.

9. Jarak dari pancing ke pemberat $2 \mathrm{~m}$.

\section{DAERAH PENANGKAPAN}

Daerah penangkapan ikan pelagis besar dan ikan demersal tersebar dari jarak 3 sampai dengan 10 mil dari Pantai Benoa Bali. Lokasi perikanan dengan alat bantu rumpon laut dalam terdapat di selatan Bali.
Pemasangan alat bantu rumpon bertujuan untuk mengumpulkan ikan supaya jarak tempuh melaut tidak terlalu jauh, dan menghemat bahan bakar minyak. Pengoperasian pancing tegak juga berada di sekitar rumpon, dengan jumlah rata-rata setiap kapal 10 gulung, dan setiap gulung 7 mata pancing dengan menggunakan umpan ikan layang (Decapterus russelii) dan lemuru (Sardinella longiceps). Seperti tertera dalam Gambar1.

\section{Desain Pancing Tegak}

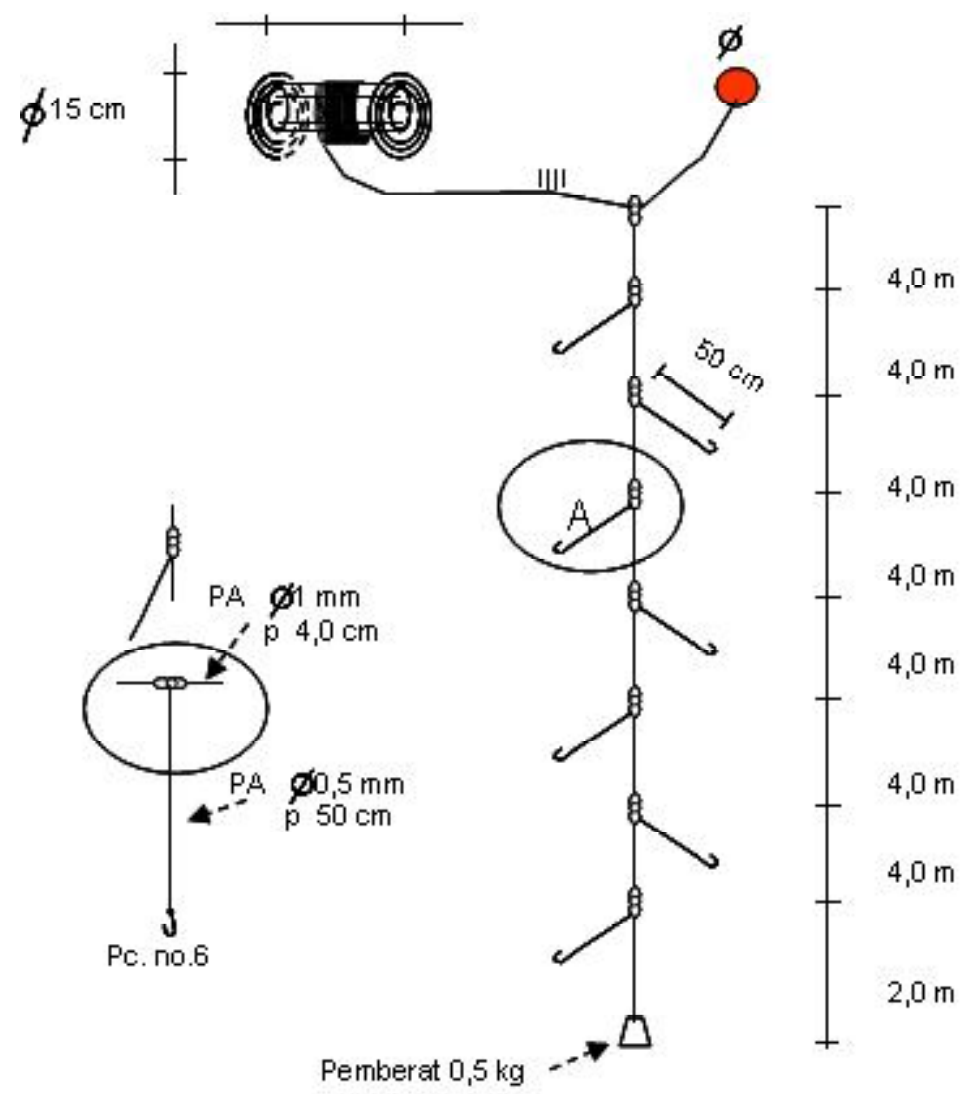

Gambar 1. Rancang bangun pancing tegak.

\section{Cara Pengoperasian Alat}

1. Pengoperasian pancing tegak dilakukan dengan kapal motor dari kayu berukuran panjang $12,0 \mathrm{~m}$; lebar 2,1 m; dalam 1,0 m; dan bobot kotor 6 GT.

2. Pengoperasian dilakukan secara bersamaan oleh 4 orang pemancing pada kanan dan kiri lambung kapal. Setiap orang hanya menggunakan 2 penggulung dengan jumlah 14 buah mata pancing.

3. Penangkapan dilakukan mulai pukul 05.00 sampai dengan 12.00 waktu setempat. Lama menunggu setiap penurunan pancing berkisar antara 5 sampai dengan 10 menit, kemudian pancing dinaikkan untuk diambil ikan hasil tangkapan, dan setelah selesai pancing diturunkan berulang kali sampai dengan pukul 12.00 waktu setempat.
4. Umpan yang digunakan adalah kembung (Restrelliger brachysoma), layang (Decapterus russelii), dan lemuru (Sardinella longiceps).

5. Penarikan pancing dilakukan secara manual dengan tenaga manusia.

6. Pengemasan ikan hasil tangkapan dilakukan dengan cara memasukkan dalam peti berisolasi dan diberi es balok.

\section{Jenis dan Komposisi Hasil Tangkapan}

Hasil tangkapan pancing tegak dari 5 kapal di perairan selatan Bali pada bulan Desember 2007 terdiri atas 4 jenis jumlah 282 ekor dengan bobot 3.334,0 $\mathrm{kg}$, dan didominasi oleh ikan cakalang (Katsuwonus pelamis) 109 ekor dengan bobot $368,0 \mathrm{~kg}$ atau 
38,65\%, madidihang (Thunnus albacares) 112 ekor dengan bobot $1.890,0 \mathrm{~kg}$ atau $39,72 \%$, mata besar (Thunnus obesus) 31 ekor dengan bobot $870,0 \mathrm{~kg}$ atau $10,99 \%$, tertera dalam (Tabel 2 ).

\section{Ukuran Ikan}

Contoh ukuran panjang dan bobot cakalang (Katsuwonus pelamis) dapat diukur 27 ekor, dengan kisaran 49,0 sampai dengan $58,5 \mathrm{~cm}$, dengan bobot 1,9 sampai dengan $2,9 \mathrm{~kg}$, madidihang (Thunnus albacares) dapat diukur 27 ekor, dengan kisaran 48,0 sampai dengan $57,0 \mathrm{~cm}$, dengan bobot 2,5 sampai dengan $3,8 \mathrm{~kg}$, dan tuna mata besar (Thunnus obesus) dapat diukur 27 ekor, dengan kisaran 39,5 sampai dengan $57,0 \mathrm{~cm}$, dengan bobot 1,3 sampai dengan $3,6 \mathrm{~kg}$ (Tabel 3).

Tabel2. Komposisi hasil tangkapan pancing tegak dari 5 kapal di perairan selatan Bali dengan pendaratan di Benoa Bali, bulan Desember 2007

\begin{tabular}{clccc}
\hline \multirow{2}{*}{ No. } & \multicolumn{1}{c}{ Jenis ikan } & \multicolumn{2}{c}{ Hasil tangkapan } & \multicolumn{2}{c}{$\begin{array}{c}\text { Persentase } \\
\text { (Ekor) }\end{array}$} \\
\cline { 3 - 4 } & & (Ekor) & $\mathbf{( k g )}$ & 10,99 \\
1. & Tuna mata besar (Thunnus obesus) & 31 & 870 & 39,72 \\
2. & Madidihang (Thunnus albacares) & 112 & 1.890 & 38,65 \\
3. & Cakalang (Katsuwonus pelamis) & 109 & 368 & 10,64 \\
4. & Baby tuna & 30 & 206 & $\mathbf{1 0 0 , 0 0}$ \\
\hline
\end{tabular}

Sumber: Hasil wawancara dengan nahkoda kapal

Tabel 3. Ukuran panjang dan bobot ikan hasil tangkapan pancing tegak dari 5 kapal di perairan selatan Bali dengan pendaratan di Benoa Bali, bulan Desember 2007

Jenis ikan: tuna mata besar (Thunnus obesus)

\begin{tabular}{ccccccccc}
\hline No. & FL (cm) & Bobot $(\mathbf{k g})$ & No. & FL (cm) & Bobot (kg) & No. & FL (cm) & Bobot (kg) \\
\hline 1. & 47,5 & 2,1 & 10. & 54,5 & 3,1 & 19. & 57,0 & 3,6 \\
2. & 52,0 & 2,8 & 11. & 42,5 & 1,4 & 20. & 54,5 & 3,1 \\
3. & 49,0 & 2,3 & 12. & 39,5 & 1,3 & 21. & 52,0 & 2,8 \\
4. & 45,5 & 1,7 & 13. & 45,5 & 1,8 & 22. & 47,5 & 2,1 \\
5. & 42,5 & 1,4 & 14. & 52,0 & 2,8 & 23. & 49,0 & 2,3 \\
6. & 39,5 & 1,3 & 15. & 47,5 & 2,1 & 24. & 54,5 & 3,1 \\
7. & 45,5 & 1,8 & 16. & 49,0 & 2,3 & 25. & 42,5 & 1,4 \\
8. & 45,5 & 1,7 & 17. & 45,5 & 1,7 & 26. & 39,5 & 1,3 \\
9. & 52,0 & 2,8 & 18. & 45,5 & 1,7 & 27. & 45,5 & 1,8 \\
\hline
\end{tabular}

Jenis ikan: madidihang (Thunnus albacares)

\begin{tabular}{ccccccccc}
\hline No. & FL $\mathbf{( c m})$ & Bobot $(\mathbf{k g})$ & No. & FL (cm) & Bobot $(\mathbf{k g})$ & No. & FL $(\mathbf{c m})$ & Bobot $(\mathbf{k g})$ \\
\hline 1. & 45,5 & 2,5 & 10. & 52,0 & 3,2 & 19. & 52,0 & 3,2 \\
2. & 48,0 & 2,8 & 11. & 52,5 & 3,2 & 20. & 54,5 & 3,4 \\
3. & 49,0 & 2,9 & 12. & 52,5 & 3,2 & 21. & 57,0 & 3,8 \\
4. & 45,0 & 2,5 & 13. & 54,5 & 3,4 & 22. & 53,5 & 3,3 \\
5. & 52,0 & 3,2 & 14. & 57,0 & 3,8 & 23. & 45,5 & 2,5 \\
6. & 52,5 & 3,2 & 15. & 52,5 & 3,2 & 24. & 45,5 & 2,5 \\
7. & 52,5 & 3,2 & 16. & 52,5 & 3,2 & 25. & 48,0 & 2,8 \\
8. & 52,0 & 3,2 & 17. & 52,0 & 3,2 & 26. & 48,5 & 2,8 \\
9. & 53,5 & 3,3 & 18. & 53,5 & 3,3 & 27. & 49,0 & 2,9 \\
\hline
\end{tabular}

Jenis ikan: cakalang (Katsuwonus pelamis)

\begin{tabular}{ccccccccc}
\hline No. & FL $\mathbf{( c m})$ & Bobot $(\mathbf{k g})$ & No. & FL (cm) & Bobot (kg) & No. & FL (cm) & Bobot (kg) \\
\hline 1. & 57,5 & 2,8 & 10. & 51,5 & 2,2 & 19. & 55,5 & 2,4 \\
2. & 55,5 & 2,4 & 11. & 50,0 & 1,9 & 20. & 58,5 & 2,9 \\
3. & 55,5 & 2,4 & 12. & 50,0 & 1,9 & 21. & 58,0 & 2,9 \\
4. & 58,0 & 2,9 & 13. & 51,0 & 2,2 & 22. & 51,5 & 2,2 \\
5. & 49,0 & 1,9 & 14. & 50,5 & 2,0 & 23. & 58,0 & 2,9 \\
6. & 49,5 & 1,9 & 15. & 49,5 & 1,9 & 24. & 57,5 & 2,8 \\
7. & 50,0 & 1,9 & 16. & 49,0 & 1,9 & 25. & 55,5 & 2,4 \\
8. & 50,2 & 2,0 & 17. & 57,5 & 2,8 & 26. & 55,5 & 2,4 \\
9. & 51,0 & 2,2 & 18. & 55,5 & 2,4 & 27. & 58,0 & 2,9 \\
\hline
\end{tabular}

Sumber: K.M. Putra Gonjeng 01 P.T. Mina Asih Benoa Bali 


\section{KESIMPULAN}

1. Pancing tegak dioperasikan secara manual, setiap gulung terdiri atas 7 buah mata pancing ukuran no. 6 yang dipasang secara tegak pada monofilament diameter $2 \mathrm{~mm}$, panjang 40 sampai dengan $200 \mathrm{~m}$. Di mana setiap kapal dilengkapi 10 unit penggulung pancing.

2. Umpan yang digunakan adalah jenis-jenis ikan pelagis kecil, terutama kembung (Restrelliger brachysoma), layang (Decapterus russelii), dan lemuru (Sardinella longiceps).

3. Hasil tangkapan pancing tegak pada bulan Desember 2007 terdiri atas 4 jenis dan didominasi oleh madidihang (Thunnus albacares).

\section{DAFTAR PUSTAKA}

Mertha, I. G. S. 2004. Laporan akhir tahun 2004 (tidak diterbitkan). Balai Riset Perikanan Laut. Jakarta.

Uktolseja, J. C. B. 1997. Laporan penelitian indeks kelimpahan ikan tuna dan cakalang di sekitar rumpon (tidak diterbitkan). Balai Penelitian Perikanan Laut. 129 hal.

\section{UCAPAN TERIMA KASIH}

Penulis menghaturkan terima kasih sebesar-besarnya pada Prof. Dr. I.Gede Sedana Merta, M.Sc., dan Dr. Wijopriono, M.Sc. yang telah memberikan saran dan koreksinya, juga pada pengetik naskah, dan penerbit sehingga dapat terlaksananya tulisan ini 